never distinguishes one disease from another, but always differentiates or diagnosticates it. His patient's mouth is an oral cavity. His jaw is a maxilla. His brain is a cerebrum, his hip joint is a coxofemoral articulation. If his eyelids are adberent, it is a case of ankylo-symblepharon. If he discovers wrinkles on the skin, they are corrugations or else rugosities. He never sees any bleeding, but only hemorrhage, or sanguineous effusion. He does not examine a limb by touch or by handling-he palpates or manipulates it. If he finds it hopelessly diseased he does not cut it off-that is undignified. He gets out his armamentarium and amputates it.

I like the sturdy contempt of our English brethren for all mere word pomp and prudishness. In London they still call their most fashionable avenue for horseback riding by its ancient name of "Rotten Row." In Chicago we would long ago have changed it to "Grand Washingtonian Cavalry Boulevard."

The surgeon over there generally shows the same solid traits as their other writers, and you will do well to study the writings of the eminent Frederick Treves of London, as a model in this respect.

A good British surgeon has good culture and good common sense combined. He takes his trocar and taps a dropsy, for instance. Not so the American. $\mathrm{He}$ blushes to hear such plain speech from his British brother, but he takes his armamentarium and goes out straightway and performs paracentesis abdominis. Still the pompousness is not all on one side of the ocean, and it is refreshing to see an occasional touch of it beyond the seas, just to show that we are not the only sinners in this respect.

A celebrated British surgeon explains his opinions as follows: "Septic peritonitis, save where definable from evidence wholly extrinsic to the condition of the peritoneum, is an etiologic entity which exists only in the mind of the pathologic metaphysician." Nothing worse than this was ever written on our side of the water.

Two of the stilted phrases which have recently gotten into vogue are etiologic factor and etiologic entity. They are both snobbish substitutes for the plain English word, cause.

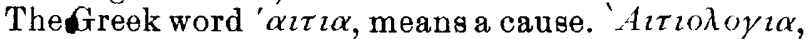
from which we derive etiology, is compounded of

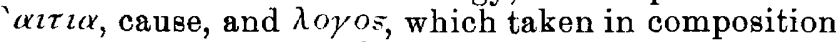
means a study or science. The whole means the

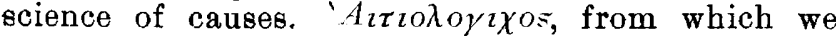
derive etiologic, means a person skilled in the study of causes, or a thing pertaining to the science of causation. Factor is a Latin word, lugged in improperly, to mix with the Greek. It is of the masculine gender and siguifies a man doing or producing something. As an English word it also has a mathematical use. Putting the whole jumble in order, an etiologic factor ought to meas some person or thing skilled in, or related to the science of causes; or, in other words, a causative-science maker, or a maker of something or of somebody pertaining to the science of causation. In the name of all the gods of Greece and Rome, what idea are these men trying to express? If they mean cause why don't they say cause and be done with it? Language is not manufactured; it grows. The speakers of each tongue have evolved it through the ages by the process of trying thousands of new words, and instinctively rejecting such as lack the music and fitness required for speaking purposes. They have tried all ways of molding words into sentences until the perfected language, like mosaic work in the hands of some great master, has become fitted to express all the high and inspiring thoughts of men.

Such a language is the pure English of to-day. Derived mainly from the Anglo-Saxon, its words are chiefly monosyllables, but they are all gems, and all polished and fitted to each other by ages of use. Whoever is master of it, is an artist in the highest sense. Whoever thrusts into it a rough, harsh, polysyllabic word, crudely quarried out of a Greek or Latin dictionary, is like a fool who drives a pickaxe through a magnificent mosaic picture, and then plugs the hole with a brickbat.

The author who dumps upon us a book full of long and ragged new words, merely to display his knowledge of ancient languages, shows his ignorance of English, and brande himself as a bungler and a literary blockhead.

As I said before, use newly coined words sparingly, but when they become necessary, select them as carefully as you would choose jewels for your bride. Fit them, polish them, and make them suitable for flashing forth the best thoughts of human souls.

It is curious that the half-educated man who knows little or nothing of the classics, always dotes most on these big phrases, and is ever foremost in piling up the abominable rubbish-heap of long, scraggy words which deform medical literature, and render it a melancholy spectacle to gods and men.

The evil is intolerable, and in your day a reform will be demanded. Bear in mind that your lives are to be spent in an atmosphere of higher culture than that of your predecessors.

The finer culture of the future will demand a reorganization of our word system, and will cast to the moies and the bats very much worthless material which is now the pride of the ignoramuses who invented it. Prepare yourselves therefore for the change, and do your best to make the language of future science more bright, pure and simple, and more fit for the use of all who wish to couple clearness of thought with beauty of expression.

\section{SOCIOLOGY AND CRIMINOLOGY.}

Address at opening of Department of Sociology and Criminology, at the Medico-Legal Congress.

\section{BY CLARK BELL, EsQ.} NEW YORK.

That public interest in sociologic studies is on the increase in our day, can not be questioned. We may recognize its hold on popular thought, by remarking that in the present Congress more papers are contributed to the Department of Sociology and Criminology, than to any other. This is not in my opinion the result of chance, but is due to the increasing interest manifested in the world of thought in this domain of scientific investigation.

Especial stimulus has been given to the study of criminology by Lombroso's writings, and others of his school.

Enricco Ferri has touched it with his brilliant lance. Herman Kornfeld, Morris Benedikt, Kraft Ebbing, Morel, Le Grand du Saulle, Brierre du Bois Mont and Prosper Depine on the continent; Havelock Ellis, W. W. Ireland, Pritchard, Thomson, Dr. Nicholson and W. Douglass Morrison in Great Britain, and many other writers of distinction have illumined its 
importance. The International Congress of Penal Law, attracted twice, many great names from all the world, to this subject.

It is not crime alone that we study now, with method of punishment, sentences, prisons and their management, including discipline and corporal punishment in prisons, all the offenses and the modifications in penal statutes, but we are coming to study more, the criminal himself, his characteristics, degeneracy, heredity, and above all environment.

Are punishments for crime, as defined in our penal statutes, really deterrent? Has the State the moral right to inflict punishment in any retaliatory spirit as is now oftentimes the basis of penal statutes? and if experience demonstrates that excessive or pre. scribed forms of punishment do not act in fact as a deterrent in diminishing crime, should we not consider with greater care what modifications are proper to reach the end desired, beside the protection of society, a perceptible decrease in the volume of crime?

The lesson of the repeal of long list of capital offenses in Great Britain since the day when sheep stealing was a capital offense, must not be lost. Severity of punishment does not appear to operate as a deterrent. It seems to be true that the fear of the scaffold rarely deters the murderer.

Crime seems in the ocean of humanity, to be the sum of social causes, which, like great rivers, flow toward and empty into it. Its Amazon is, no doubt, alcoholic stimulants which more than all other causes combined, constitute the inevitable, terrible, irresistible scourge of the race. In its currents, tides and eddies, are insanity, epilepsy and physical degeneracy, not always in the parent, but more certain in the offspring. Its movements run like the blood of man into the veins and lives of children's children, with a taint as terrible as that of leprosy or syphilis.

The burdens to the State for the care of the insane in the rural districts or counties, notably in an agricultural county like Yates, where $I$ reside in the summer, in this year of grace is actually greater than the cost of the schools, and almost equal to the entire other expense of the State government including the canals.

When will we have the courage to look this awful question squarely in the face, and decrease the volume of crime, not by penal laws for the punishment of the criminal (often the victim of his birth and environment) but by striking at and repressing the cause.

The recognized defects in our penal laws, especially in Great Britain, the United States and many of the continental states may be summarized as follows:

1. The principle of equality of sentences, as to their duration as now existing, is erroneous and vicious in its fundamental principles.

2. It is wrong to make arbitrary punishments for the same offenses against all offenders alike.

3. Criminal laws must be so framed as to meet the social conditions of the criminal classes.

Laws based upon the social conditions of men in the ordinary walks of life, fail. They should rather be aimed at the social life and condition of the criminal classes. I quite agree with W. Douglass Morrison of the Wadsworth Prison in England, when he asserts that: "The criminal is a product of anomalous biologic conditions, as well as adverse circumstances."

4. Some plan should be devised in the administration of punishments to offenders, under which the principle of determinate sentences should be applicable to the individual condition of the offender. For example: $(a)$, the same offense should not receive the same punishment in all cases, as for example, when committed by an adult, or a child or a youthful offender; $(b)$, the difference in punishment for the same offense by a man and by a woman, should be rather to the man and the woman.

5. We must consider whether Bentham was right in insisting that we should, in adjusting our methods of punishment, look as much to the nature and condition of the offender as to the nature of the offense. Much of the failure of our present system as a protection to society is unquestionably due to our ignoring this fundamental law in our present penal statutes, and punishment of criminals.

Mr. Morrison strikes at an important principle, that we should place our prisons on the same basis as the penal laws. That prisons should reach the causes and conditions which produce the criminal, and the penal statutes be placed on the same plane.

\section{ORIGINAL ARTICLES.}

\section{PROGNOSTIC SIGNIFICANCE OF ALBUMI- NURIC RETINITIS.}

Read in the Section on Ophthalmology, at the Forty-sixth Annual Meeting of the American Medical Association, at Baltimore, Md., May 7-10, 1895.

BY E. OLIVER BELT, M.D.

PROFESSOR OF OPHTHAIMOLOGY AND OTOLOGY, HOWARD UNIVERSITY, AND OPHTHALMIC AND AURAL SURGEON TO FREEDMAN'S HOSPITAI. WASHINGTON, D. C.

It seems to be generally admitted that the retinitis following scarlet fever and pregnancy is not of special prognostic significance as to vision or mortality, for under careful treatment recovery of both vision and health are not unusual in these cases. Therefore in this paper, such cases have been excluded, as the prognosis is altogether different and unfavorable in the retinitis of chronic Bright's disease. Though improvement of vision very frequently occurs in albuminuric retinitis, it is of minor importance in comparison with the life of the patient, and the main point which I wish to determine is the average duration of life after the appearance of retinitis from renal disease. The statistics heretofore published upon this subject deal mostly with hospital cases, in which the duration of life rarely exceeds one year. Occasionally we see reported a case in private practice which has survived five, ten, and even fifteen years (Noyes mentions one of ten years, and Webster re. ports the case of a minister who survived seventeen years). This led me to think that we might be able to give a more hopeful prognosis in cases which could receive good medical attention with the proper hygienic surroundings, and I decided to try and find, whether or not the average duration of life was greater among private than among hospital cases. With this end in view, a few weeks ago I requested quite a number of ophthalmologists throughout the country to report the cases which had occurred in their private practice to me. The time allowed was too short for many to look over their records, and many had not kept trace of the patients after referring them back to the family physician, but enough cases were reported to show that the duration of life is longer among private patients, and that renal affection is undoubtedly influenced by hygienic sur- 